\title{
Woody Species Diversity and Forest Structure from Lowland to Montane Forest in Hyrcanian Forest Ecoregion
}

\author{
Seyed Mohammad JAFARI ${ }^{*}$, Shahin ZARRE $^{2}$, Seyed Kazem ALAVIPANAH ${ }^{3}$ \\ 1 School of Biology and Center of Excellence in Phylogeny of Living Organisms, College of Science, University of Tehran, P.O. \\ Box 14155-6455, Tehran, Iran \\ 2 School of Biology and Center of Excellence in Phylogeny of Living Organisms, College of Science, University of Tehran, \\ Tehran, Iran
}

3 Department of Cartography, Faculty of Geography, University of Tehran, Tehran, Iran

*Corresponding author, e-mail: smjafari@ut.ac.ir

(C) Science Press and Institute of Mountain Hazards and Environment, CAS and Springer-Verlag Berlin Heidelberg 2013

\begin{abstract}
Alborz Mountains host Caspian Hyrcanian forest ecoregion along the northern slopes and forest steppe ecoregion in highlands. Hyrcanian forest covers the southeastern part of Caucasus biodiversity hotspot and is of great biogeographic importance. Altitudinal pattern and correlation between woody species biodiversity (DIV), forest structure ((stem density (DEN), mean basal area (MBA) and mean height class (MHC)) and disturbance (DIS) were explored along 2,400 $\mathrm{m}$ altitudinal gradient in Hyrcanian relict forest, Central Alborz Mountains. Vegetation changes from lowland forest (LoF) to midaltitude forest (MiF) and montane forest $(\mathrm{MoF})$ in this area. The altitudinal gradient was divided into twelve $200 \mathrm{~m}$ elevational belts. Point centered quarter method (PCQM) with 96 sampling points and 83 vegetation samples by plot method (PM) were used to record field data. Shannon-Wiener index and Pearson coefficient were used for diversity and correlation analysis. The results showed that DEN decreased linearly, MBA and MHC showed relatively hump shaped and DIS showed a reverse hump shaped pattern of change along altitudinal gradient. Woody species diversity decreased non-steadily from LoF to MoF. Transitional vegetations of Carpinus-Fagus and Fagus-Quercus represented higher diversity of woody taxa compared to adjacent homogenous communities. Significant correlation was observed between altitude and all parameters: DEN with MBA, DIS and DIV; MBA with DIS; MHC with DIS along with DIV; and DIS with DIV at the study area scale. Surprisingly,
\end{abstract}

Received: 8 January 2013

Accepted: 24 May 2013 correlation between studied parameters differed within each vegetation type. Altitude probably acts as a proxy for human and environmental driving forces in this area. Stability of warm and wet condition, season length, soil depth along with forest accessibility probably influences the altitudinal pattern of the studied parameters. Disturbance affects forest structure and consequently diversity; especially in lowlands. The obtained results recommend using both forest biodiversity and mensuration data in management process of forest ecosystems.

Keywords: Alborz Mountains; Biodiversity; Forest Mensuration; Hyrcanian forest; Disturbance

\section{Introduction}

Conservation of biological diversity has become a core concern for forest management during last decades. Abiotic factors and biotic trade-offs determine biodiversity and affect functioning of forest systems (Scherer-Lorenzen et al. 2005). Climate change, habitat loss, biological invasions, environmental pollution, land use/land cover changes and human exploitation are among the most important influencing factors for biological diversity. These factors and their impacts on biological diversity; especially within forest ecosystems, are well represented in ecological literature (e.g., Clark and Covey 2012; Khaledian et al. 2012; Mantyka-Pringle et al. 2012). 
There is scientific consensus on the importance of climatic parameters, topography, area, speciation rate, biotic interactions and spatial distribution of these parameters for forest biodiversity (see Evans 2001). In addition, disturbance, both natural perturbations and human interference, is undoubtedly a key driving force of forest biological richness (Johnson and Miyanishi 2007). However, relationship between forest structural parameters, disturbance and biodiversity has been primarily explored during last decade (e.g., Estevan et al. 2007; Sahu et al. 2012). Structural characteristics such as patch size, canopy density, basal area and canopy height can exert considerable influence on habitat diversity, biotic interaction, gene flow and subsequently forest species and vegetation diversity. Linking forest structure and diversity is of utmost importance in ecological forestry and forest management.

Using environmental gradients has helped forest ecologists and management parties to survey forest response to change in a specific parameter along with observing inter-relationships of forest components and properties (Lafortezza et al. 2008). Altitudinal pattern of changes in forest structure and diversity has always been an interesting topic for ecologists. Several important environmental factors for plant life may co-vary with elevation such as precipitation, temperature, soil depth, season length, wind speed, irradiation intensity, pollinators and dispersal agents along with spatial and temporal variation of these parameters (McCain and Grytnes 2010). Changes in plant community type and dynamics along altitudinal gradients have been undoubtedly underrepresented in ecological literature (e.g., Pellissier et al. 2010; Bodin et al. 2013).

Hyrcanian (Caspian) forest is one of the relict patches of the broad-leaved forests that once covered most of the Eurasia, 25-50 million years ago, in the early Cenozoic Era (Ramezani et al. 2008). It is located at the southeastern part of Caucasus Biodiversity Hotspot and covers Northern slopes of Alborz Mountains. Elevation ranges from about zero up to $2,800 \mathrm{~m}$ a.s.l. in this forest. Vegetation shifts from lowland forest (LoF) of lower altitudes in the northern part to Midaltitude forest (MiF) mainly between $800 \mathrm{~m}$ and $1,600 \mathrm{~m}$ a.s.l. and to montane forest (MoF) in the southern highlands. Generally, this forest is dominated by tertiary relict woody flora and represents a great biogeographic value for the region. From the plant geography point of view, the Hyrcanian ecosystem is known as Hyrcanian subprovince from Euro-Siberian region of Holarctic kingdom. Altitudinal pattern of changes in forest structure, biological diversity and functional diversity in Hyrcanian forest is poorly studied (e.g., Eshagi Rad and Shafiei 2010; Siadati et al. 2010). In addition, much less attention has been paid to relationships among species diversity, forest structure and disturbance. Because of increasing rate of clear-cutting and over-exploitation, study of forest components, their relationships along with disturbance effects is an urgent need for efficient management and conservation of this unique ecosystem. The relationships between forest structural parameters and diversity have been explored in various ecosystems. This research, for the first time, explore the above-mentioned relationships in Hyrcanian relict forest ecosystem.

This study tries to answer the following questions:

Q1. How forest density (DEN), mean height class (MHC) and mean basal area (MBA) change from lowland to montane forest along $2,400 \mathrm{~m}$ altitudinal gradient?

Q2. How diversity of woody species (DIV) and forest disturbance (DIS) change with altitude?

Q3. Is there any correlation among structural, diversity and disturbance parameters in Hyrcanian forest?

\section{Materials and Methods}

\subsection{Study area}

The present study was conducted during vegetative seasons of 2009-2010 in forest ecosystem of Central Alborz Protected Area (CAPA), between $36^{\circ} 28^{\prime}-36^{\circ} 38^{\prime}$ Northern latitudes and $51^{\circ} 22^{\prime}-51^{\circ} 30^{\prime}$ Eastern longitudes, Northern Iran (Figure 1). This forest area, which is completely located on Northern slopes of Alborz Mountains, covers about 7,450 ha surface area. Altitude ranges from 100 to $2,400 \mathrm{~m}$ a.s.l. in this forest. Precipitation decreases from about $1,300 \mathrm{~mm}$ in the northern coastal part to $800 \mathrm{~mm}$ in the 


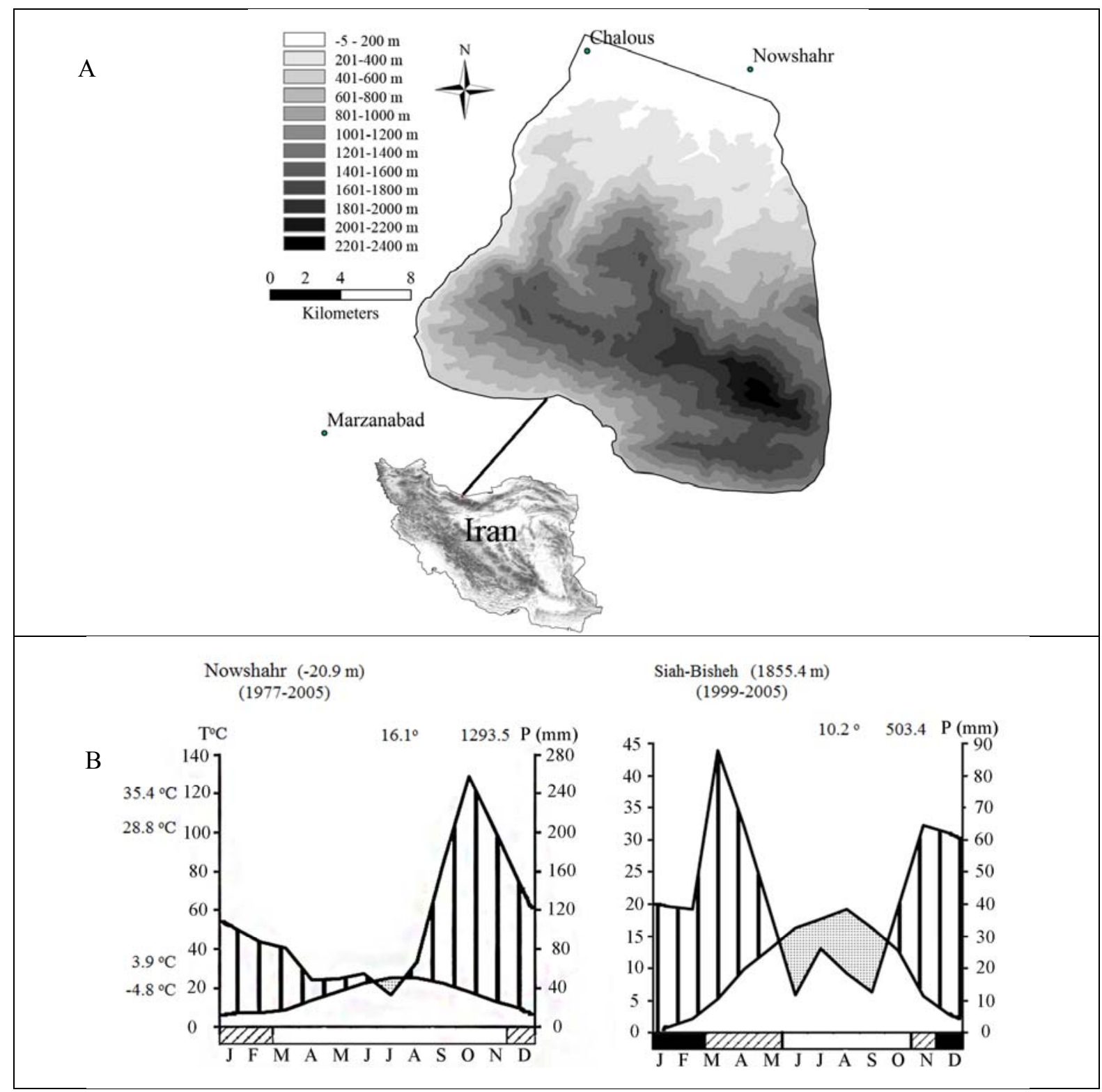

Figure 1 Physical geography of the study area and climate condition of two places. (A) Geographical location and digital elevation model (B) Climate data obtained from the online database of Iran Meteorological Organization (http://www.irimo.ir/).

southern highlands. The maximum precipitation mainly occurs during November - January time period in lowland which shifts to March - May time period in highlands. Lowlands of Hyrcanian ecoregion experience minimum precipitation during June - July, however this time period extends from June to September in highlands. This forest ecoregion represents semi-tropical condition in lowlands including relatively constant humidity as rain or fog, warm thermal condition and dense epiphytic vegetation cover. In spite of small size of the area, North-South and West-East pattern of decrease for humidity along the northern slopes of
Alborz Mountains can be clearly observed (Khalili 1973). Mean annual temperature decreases from $16.1^{\circ} \mathrm{C}$ for Nowshahr station in the northern coastal part, to $10^{\circ} \mathrm{C}$ in Marzan-abad in the southwestern and to $12.2^{\circ} \mathrm{C}$ in Kojur in the southeastern part (Figure 1). Southern slope of Alborz Mountains in the area experiences about $400 \mathrm{~mm}$ precipitation and has Mediterranean type of climate and vegetation. These slopes in our study area are covered by Cupressus sempervirense L. woodlands which occur as few relict patches in Iran. Warm and dry condition is characteristics of Southern slopes of Alborz Mountains especially during 
summer season.

\subsection{Altitudinal zonation and disturbance scaling}

The main altitudinal gradient was subjectively divided into twelve 200 m elevational belts. First, we selected three $800 \mathrm{~m}$ altitudinal belts as proxies for vegetation types. The next aim was to explore altitudinal variation within each vegetation type. Therefore, we subjectively divided each vegetation belt into four $200 \mathrm{~m}$ altitudinal belts. Two simple indicators of forest disturbance (DIS) were used: (i) number of fallen logs and trunks (NFL) and (ii) vegetation crushing intensity (VCI) (Table 1). Woody logs, decaying or fresh, were counted within a radius of $100 \mathrm{~m}$ surrounding sampling point. The woody logs which were completely or partly located within the sampling radius, natural or human disturbances as well as all size classes of fallen woody logs were treated similarly. The minimum length of 1 meter and diameter of $20 \mathrm{~cm}$ was considered for fallen logs to be counted. Selective logging affects spatial random distribution of disturbance events in this forest. We found more fallen logs in forest communities dominated by main timber taxa. Since the focus of this study was on woody species diversity and forest structure, fallen woody debris played more important role in disturbance scaling.

Vegetation crushing may result from recreational and hiking activities, skidding and logging machinery along with ranching practices within forest ecosystem. The crushing intensity can be estimated using different indicators including signs of grazing, trampling as well as left trails of vehicles. Grazed plants; which have normally herbaceous habit, distinguishably lose upper part of stem or leaves. Ranching and hiking activities normally leave flattened herbaceous vegetation, however, the logging machinery squash the herbaceous plants on forest floor. We used a visual comparative approach to scale crushing intensity (low, medium, high) within a radius of $100 \mathrm{~m}$ surrounding sampling point. Prior to disturbance scaling, the sampling points (with $100 \mathrm{~m}$ radius) were inspected thoroughly for signs of vegetation crushing. Then, the percentage cover of the crushed vegetation was estimated within $100 \mathrm{~m}$ radius surrounding sampling points. We placed o$10 \%$ crushed vegetation as low, $10-25 \%$ as medium and above $25 \%$ as high vegetation crushing intensity (Table 1).

\subsection{Forest structure}

Mensuration parameters of forest stands were calculated using Point-Centered Quarter Method (PCQM) (Cottam and Curtis 1956). According to PCQM, a West-East line transect was established in each elevational belt along which sampling points were chosen based on random numbers, starting from western border of the area. Based on the surface area of the belts, 6-10 sampling points with 200 meter minimum distance were considered which resulted into 96 sampling points for the whole area. Using GPS, each sampling point was divided into four quarters in which distance to center, taxonomic identity and diameter at breast height (DBH) were recorded for two nearest woody taxa. One nearest taxon is normally measured in standard PCQM methodology; however, we decided to record two nearest taxa in each quarter to increase the reliability of the data. In case of multi-stemmed trees, DBH of individual stems were measured and summed. For choosing nearest stems, $10 \mathrm{~cm}$ minimum threshold of diameter was considered. In addition to normal data types of PCQM, height of sampled trees, along with disturbance severity; including VCI and NFL, were recorded for each sampling point. Using distance to center and $\mathrm{DBH}$, structural parameters of forest stands such as DEN and MBA were calculated (Mitchel 2010).

Table 1 Data scales used in Point-Centered Quarter Method (PCQM) to record plant height and disturbance in Hyrcanian Forest. Four quarters of sampling points were determined using GPS.

\begin{tabular}{l|l|l} 
Quarter & Height class (m) & Forest disturbance scale \\
& $1=0-5$ & $1=$ Undisturbed \\
$1=\mathrm{NW}$ & $2=5-10$ & 2 = Low disturbance (up to 2 logs + low vegetation crushing) \\
$2=\mathrm{NE}$ & $3=10-20$ & $3=$ Medium disturbance (2-4 fallen logs + medium vegetation crushing) \\
$3=\mathrm{SE}$ & $4=20-30$ & $4=$ High disturbance (more than 4 logs + high vegetation crushing) \\
$4=\mathrm{SW}$ & $5=30-40$ &
\end{tabular}




\subsection{Woody species composition}

Species composition of forest stands was recorded using standard vegetation sampling method; the Plot Method (PM) (Braun-Blanquet 1932). Generally, 6-8 vegetation plots, with $400 \mathrm{~m}^{2}$ surface area, have been established in each belt which led to 83 vegetation plots for the whole area. Presence and cover-abundance of all woody vascular plants were recorded. We located the vegetation plots at PCQM sampling points synchronously. Based on plot data, alpha diversity (DIV) was calculated for each elevational belt. (Appendix 1).

\subsection{Statistical Analysis}

In order to compare altitudinal belts as twelve large sampling areas, a belt-wise statistical analysis was employed in this study. Mean parameters such as mean altitude, MBA, MHC, mean DEN and mean DIS were calculated or measured for each belt. We used minimum and maximum elevations of each belt to produce mean altitude. Eight height values of recorded stems in each sampling point (two stems in each quarter) were summed and averaged. The obtained value was placed as mean height class for corresponding sampling point (Table 1). Mean height class of all sampling points within each altitudinal belt were averaged which generated the mean height class of the belt. Similarly, basal area and cover of eight taxa were calculated using DBH and distance to center values in each sampling points and then averaged. The resulted mean basal area and mean cover values of all sampling points in each belt were used to produces density and basal area values of elevational belts (Appendix 2).

Each elevational belt was considered as a mega-plot. Cover-abundance values obtained by plot method were converted to Ordinal Transfer Values (OTVs) proposed by van der Maarel (1979) for numerical treatment. Shannon-Wiener index $(H)$ (Magurran 1988) was used to quantify alpha diversity of woody species:

$$
H=\sum_{i=1}^{S} P_{i} \ln P_{i}
$$

where $H$ represents alpha diversity, $P_{i}$ is the relative cover abundance of species in each plot, $i$ indicates species number and $S$ is the total number of species in each plot. Here, $P_{i}$ is calculated by dividing cover abundance value of the species to sum of cover abundance values of all woody taxa in each plot. The index values for all plots within each elevational belt were averaged and the resulted mean value was placed as alpha diversity value of that belt.

In order to explore correlation between altitude, forest mensuration parameters, alpha diversity of woody taxa and forest disturbance, Pearson correlation coefficient was used. Prior to analysis, we used Kolmogorov-Smirnov test to evaluate normality of data. Mean values of altitude, forest density, mean basal area, alpha diversity and mean height class were also generated for lowland (belts 1-4), mid-altitude (belts 5-8) and montane (belts 9-12) forest vegetations. Correlation analysis was performed at both vegetation type and whole forest scale. All statistical analyses in this study were implemented using SPSS 20.0 (IBM Corp. 2011).

\section{Results}

\subsection{Altitudinal pattern of forest disturbance and diversity (Question 2)}

Using plot method, 39 woody species were recorded in this study (Appendix 1). DIV decreased from LoF to MiF, then leveled up in MoF (Figure $2 \mathrm{~A}$ and $2 \mathrm{~B}$ ). The surface area of the belts decreases constantly along altitudinal gradient; however DIV values represented a general reverse hump-shaped pattern of change (Figure 2B). The minimum alpha diversity of woody species occurred at 1,200-1,400 m a.s.l. DIV values decreased from Fagus-Quercus transitional community $(1,600-2,000 \mathrm{~m})$ to Quercus macranthera woodlands at montane elevations (2,000-2,400 m) (Figures $2 \mathrm{~A}$ and $2 \mathrm{~B}$ ). Despite small increase of DIV values from $\mathrm{B} 1$ to $\mathrm{B} 2-$ 3 (Figure 2B), a considerable decrease of ShannonWiener Index occurred between $\mathrm{B}_{4}$ (2.93) and $\mathrm{B}_{5}$ (2.32), indicating a significant difference in diversity of woody taxa at the border between LoF and MiF. Similarly, a meaningful increase of diversity was observed at the border between $\mathrm{MiF}$ and MoF, namely between B8 and B9. Mean value of Shannon-Wiener index changed from 2.98 in LoF, to 2.21 in MiF and 2.34 in MoF. 

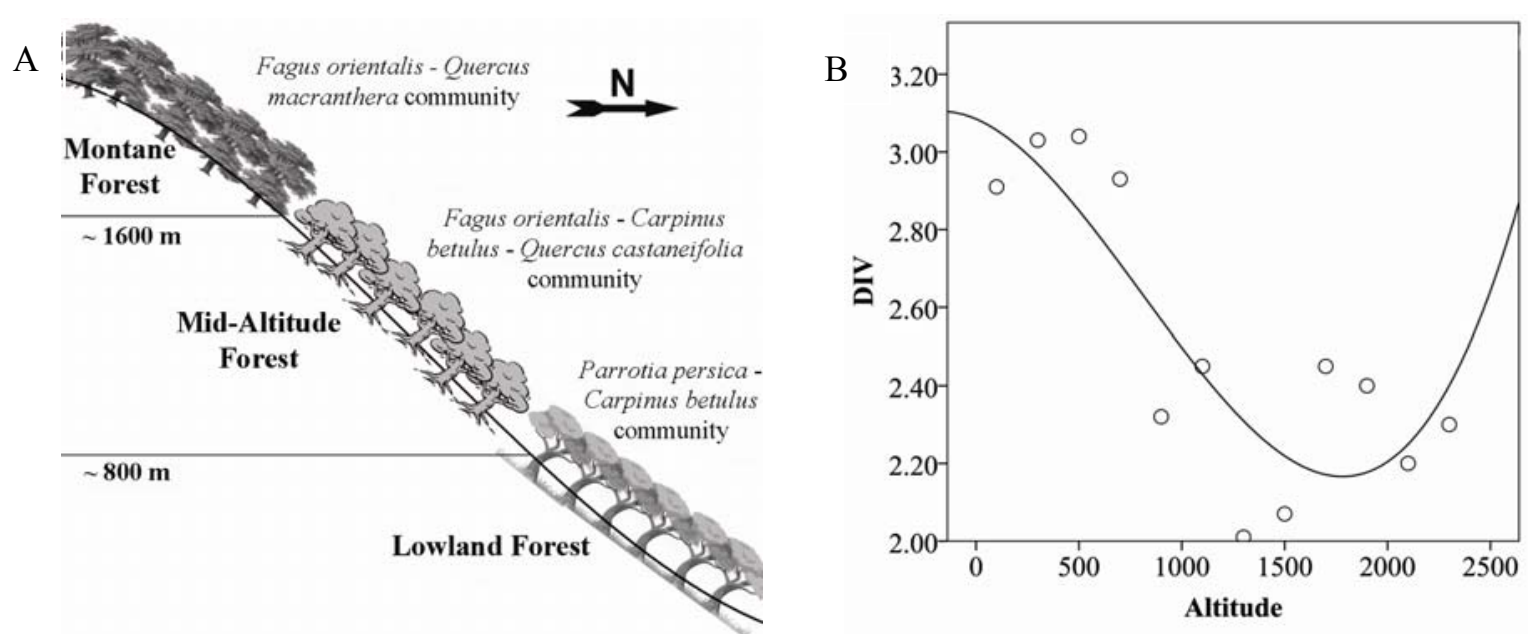

Figure 2 General vegetation profile (A) and altitudinal pattern of woody species diversity (B) in Hyrcanian forest of Central Alborz Mountains. The indicated altitudinal limits coincide with type shift in forest vegetation. These limits can be used as indicators of limits between lowland, mid-altitude and montane forest vegetations in Hyrcanian forest.

Disturbance decreased linearly from LoF to 2,000 m a.s.l. in MoF, then increased in Quercus macranthera woodlands (Figure 3A). The maximum DIS value is observed in $\mathrm{B} 1$ (3.3) and the minimum in B10 (1.7) which is positioned in Fagus-Quercus transitional community. Generally, different disturbance types in LoF, moderate logging and cutting in MiF along with grazing and trampling in MoF were observed. DIS also decreased in East-West pattern (data not shown). Forest edges including first and last elevational belts experienced highest disturbance in this part of Hyrcanian forest. Lowland forest was subject to intensive logging which has deeply affected forest structural properties in this vegetation type. Generally, DIS represented a reverse hump-shaped pattern of change in this area and the mean DIS decreases from LoF (3) to MiF (2.47) and MoF (2.01) (Figure 3A).

\subsection{Altitudinal pattern of forest structure (Question 1)}

Forest density decreased linearly from LoF (426.5 trees/ha), to $\mathrm{MiF}$ (289.25 trees/ha) and MoF (138.5 trees/ha) in this area (Figure 3B). The maximum and minimum DEN values were observed in first (462 trees/ha) and last belts (95 trees/ha) respectively. Mean DEN value for the entire study area was 285 trees/ha. Mean basal area showed a unimodal pattern of change along the altitudinal gradient (Figure $3 \mathrm{C}$ ). MBA decreased from $439.2 \mathrm{~m}^{2} / \mathrm{ha}$ in LoF to $383.7 \mathrm{~m}^{2} / \mathrm{ha}$ in $\mathrm{MiF}$ and $225.4 \mathrm{~m}^{2} / \mathrm{ha}$ in $\mathrm{MoF}$, however this decrease was not steady. In LoF, MBA increased from $420.4 \mathrm{~m}^{2} /$ ha at lower boundary of forest in first belt to $452 \mathrm{~m}^{2} /$ ha at altitudinal boundary between $\mathrm{LoF}$ and $\mathrm{MiF}$ in fourth belt (Figure $3 \mathrm{C}$ ). There was a steady pattern of more than two-fold decrease (from $417 \mathrm{~m}^{2} / \mathrm{ha}$ in $\mathrm{MiF}$ to $185.2 \mathrm{~m}^{2} / \mathrm{ha}$ in MoF) of MBA and subsequently tree volume above $800 \mathrm{~m}$ a.s.l..

A significant hump shaped pattern of change was observed for mean height of woody species in this study. Mean value of height class was 1.09, 2.02 and 1.57 in $\mathrm{LoF}, \mathrm{MiF}$ and MoF respectively (Figure 3D). The maximum $(2.3 \simeq 0.56 \mathrm{~m})$ and minimum (0.8 $\simeq 0 \quad 0.5 \mathrm{~m})$ MHC were observed in seventh and first elevation belts. In spite of categorical nature of mean height variable, mean values of height classes in each belt were considered as total MHC for that belt (Figure 3D). Apparently, montane Quercus woodland and midaltitude Fagus-Quercus-Carpinus community are dominated by shortest and tallest woody taxa respectively (Figure $2 \mathrm{~A}$ ).

\subsection{Correlation between forest mensuration parameters, disturbance and diversity (Question 3)}

Correlation analysis revealed significant relationship between altitude and selected structural, diversity and disturbance parameters 

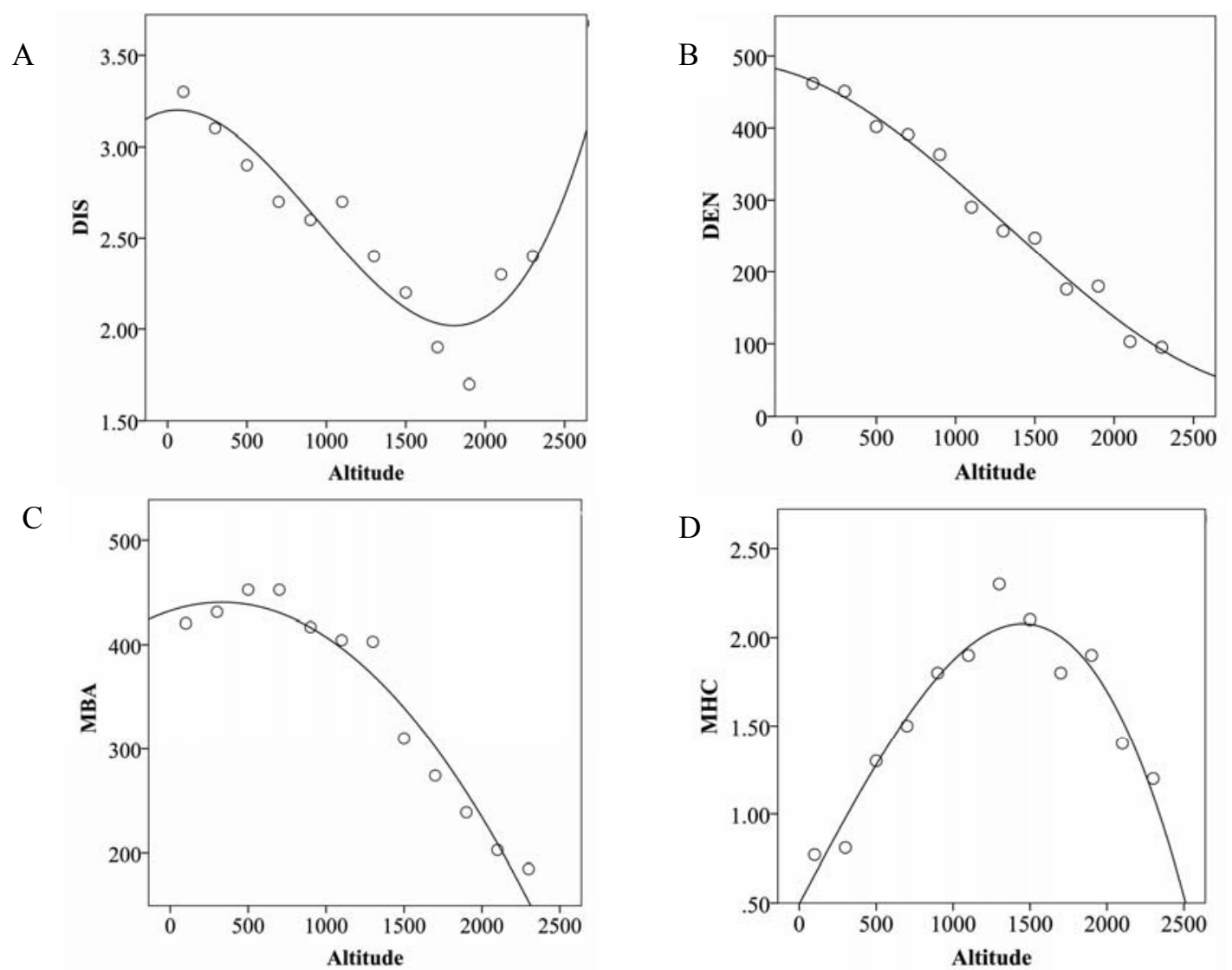

Figure 3 Altitudinal pattern of forest disturbance (DIS). (A) stem density (DEN); (B) mean basal area (MBA); (C) and mean height class (MHC) (D) in Hyrcanian forest of Central Alborz Mountains.

(Table 2). Generally, altitude was strongly correlated with DEN, MHC, DIS and DIV. Except MHC, the studied parameters showed negative correlation with altitude (Table 2). The general correlation between altitude and the studied parameters differed within LoF, MiF and MoF. Surprisingly, altitude only showed significant association with DIS in LoF $(-0.958, \rho<0.05)$, DEN in $\operatorname{MiF}(-0.972, \rho<0.05)$ and MBA in MoF $(-$ $0.997, \rho<0.01)$.

In contrast to negative relationship with altitude, DEN was positively related to MBA, DIS and DIV in the study area, however remained uncorrelated with MHC (Table 2). DEN was not associated with DIV within vegetation types, however showed positive $(0.977, \rho<0.05)$ and strong negative $(-0.998, \rho<0.01)$ correlation with MHC in MoF and LoF respectively. Similarly, DEN showed significant opposite correlation with DIS (0.960, $\rho<0.05$ in LoF; 0.967, $\rho<0.05$ in MoF) and contrasting relationship with MBA (-0.977, $\rho$ $<0.05$ in LoF; 0.929, $\rho>0.05$ in MoF) in lowland and montane forest vegetations.

MBA parameter correlated positively with DIS indicating an increase in mean basal area with increasing disturbance (Table 2). However, these parameters were uncorrelated within $\mathrm{MiF}$ (0.854, $\rho>0.05), \operatorname{MoF}(-0.812, \rho>0.05)$ and LoF (-0.941, $\rho>0.05)$. MBA was marginally correlated (0.949, $\rho \simeq 0.05)$, remained uncorrelated $(-0.796, \rho>0.05)$ and was strongly correlated $(-0.997, \rho<0.01)$ with altitude in $\mathrm{LoF}, \mathrm{MiF}$ and $\mathrm{MoF}$ respectively. Moreover, MBA showed meaningful negative correlation with DEN only in LoF $(-0.977, \rho<0.05)$ meaning a decrease in MBA with increasing stem density.

Mean height was negatively associated to DIS and DIV in this study, indicating shorter stands in both diverse and disturbed vegetations in Hyrcanian forest (Table 2). Negative relationship between MHC and DIS remained significant in LoF $(-0.955, \rho<0.05)$ and $\mathrm{MoF}(-0.967, \rho<0.05)$, however disappears in $\mathrm{MiF}(-0.662, \rho>0.05)$. In contrast to general relationship (Table 2), MHC 
Table 2 Correlation between forest structural characteristics, altitude, disturbance and woody species diversity in Hyrcanian Forest

\begin{tabular}{|l|l|l|l|l|l|l|}
\hline & Alt. & DEN & MBA & MHC & DIS & DIV \\
\hline Alt. & - & $-0.808^{* *}$ & $-0.697^{*}$ & $0.730^{* *}$ & $-0.809^{* *}$ & $-0.741^{* *}$ \\
\hline \multirow{2}{*}{ DEN } & $-0.808^{* *}$ & $\rho<0.01$ & $\rho<0.05$ & $\rho<0.01$ & $\rho<0.01$ & $\rho<0.01$ \\
& $\rho<0.01$ & - & $0.960^{* *}$ & -0.280 & $0.664^{*}$ & $0.626^{*}$ \\
\hline \multirow{2}{*}{ MBA } & $-0.697^{*}$ & $0.960^{* *}$ & $\rho<0.01$ & $\rho>0.05$ & $\rho<0.05$ & $\rho<0.05$ \\
& $\rho<0.05$ & $\rho<0.01$ & - & -0.128 & $0.666^{*}$ & 0.520 \\
\hline \multirow{2}{*}{ MHC } & $0.730^{* *}$ & -0.280 & -0.128 & - & $\rho<0.05$ & $\rho>0.05$ \\
\hline \multirow{2}{*}{ DIS } & $\rho<0.01$ & $\rho>0.05$ & $\rho>0.05$ & - & $-0.670^{*}$ & $-0.717^{* *}$ \\
& $-0.809^{* *}$ & $0.664^{*}$ & $0.666^{*}$ & $-0.670^{*}$ & $\rho<0.05$ & $\rho<0.01$ \\
\hline \multirow{2}{*}{ DIV } & $\rho<0.01$ & $\rho<0.05$ & $\rho<0.05$ & $\rho<0.05$ & - & $-0.603^{*}$ \\
& $-0.741^{* *}$ & $0.626^{*}$ & -0.520 & $-0.717^{* *}$ & $-0.603^{*}$ & $\rho<0.05$ \\
\hline
\end{tabular}

Notes: ${ }^{* *}$ Strongly significant $(\rho$-value $<0.01),{ }^{*}$ Significant $(\rho$-value $<0.05)$.

$\mathrm{DEN}$ = stem density; MBA = mean basal area; $\mathrm{MHC}=$ mean height class; DIS = disturbance; DIV= biodiversity.

was meaningfully correlated with DEN in LoF $-0.998, \rho<0.01)$ and MoF (0.977, $\rho<0.05)$, and with MBA in LoF (0.960, $\rho>0.05)$. Apparently, mean height of woody species increased with stem volume and decreased with stem density in lowland forest vegetation.

Totally, DIS correlated positively with DEN and MBA and showed negative relationship with MHC and DIV (Table 2). Co-variation of DEN and DIS occurred only in LoF $(0.960, \rho<0.05)$, however they were uncorrelated in $\operatorname{MiF}(0.710, \rho>$ 0.05) and negatively correlated in MoF $(-0.967, \rho$ $<$ 0.05). Generally, DIS showed negative association with DIV; however they are uncorrelated within three vegetation types. Similarly, DIV is associated with all studied parameters except MBA; however DIV remained independent of studied parameters within vegetation types. The total negative correlation between DIV and DIS indicated higher alpha diversity of woody species in less disturbed forest belts in our study area.

\section{Discussion}

Altitudinal pattern and correlation between structural parameters, woody species diversity and forest disturbance were explored in this study. In our study, altitude represents meaningful relationship with all studied parameters at study area scale, however; it correlates with a single parameter within each vegetation type. Apparently, either the local condition along the gradient exerts considerable affect on obtained results; or altitude acts only as a proxy for other environmental parameters.

Stem density can be considered as a function of different factors such as topography, precipitation, soil properties, disturbance and plant community structure (e.g., Slik et al. 2010). Moreover, dry season length is proposed as a climatic determinant of stem density (Ter Steege et al. 2003). The observed decreasing pattern of DEN can be attributed to increasing dry season length and decreasing precipitation with the altitude in Hyrcanian forest. The negative correlation between DEN and altitude in our study contradicts the observed positive relationship in most tropical landscapes (Givnish 1999; Slik et al. 2010) and altitude probably acts as proxy for climatic driving forces. In spite of positive correlation between DEN and DIS in LoF, intensive logging and harvesting in lowlands replace few large trees with more dense young stands (Denslow 1995). Takyu et al. (2005) found out that stem density in temperate deciduous broad-leaved and evergreen coniferous forests was lower than in tropical and temperate evergreen broad-leaved forests due to the low density of small trees (what disturbance creates in high disturbed areas). PCQM calculates stem density based on nearest stem and it considers all woody stems; with diameter above a critical size, similarly in density calculation (Mitchel 2010). Therefore, DEN value obtained by PCQM may even be larger in vegetation types with young woody taxa compared to climax stands.

Lowlands in Hyrcanian forest are 
characterized by persistent wet climate along with greater soil fertility and depth; based on which higher value of MBA is expected (Tromp van Meerveld and McDonnell 2006). Mostly negative correlation between elevation and basal area, inferred by $\mathrm{DBH}$, or relatively hump shaped pattern along altitudinal gradient were observed in other similar studies (Tromp van Meerveld and McDonnell 2006; Takeuchi et al. 2011). The increasing pattern of MBA within LoF questions our expectation however confirms the role of logging as a key factor in structuring forest in lowlands; as demonstrated by the marginal negative correlation of DIS and MBA in LoF. Stand level mean basal area normally correlates with annual rainfall, annual temperature (Slik et al. 2010), soil fertility (Moran et al. 2000), soil depth (Tromp van Meerveld and McDonnell 2006) and the size of the largest trees (Midgley and Niklas 2004); all of which decrease with altitude in MiF and MoF. Apparently, these factors override disturbance in midlands along with highlands and disturbance probably exert negligible influence on the pattern of basal area above lowlands.

Hydraulic (Koch et al. 2004) and mechanical (Niklas 2007) constraints probably limit the height to which plants can grow. Moles et al. (2009) proposed precipitation in the wettest month as a key predictor of plant height at global scale. Generally, environmental forces such as competition, vegetation properties, shade condition, temperature, humidity, plant genetics and successional stage can directly or indirectly influence stand level mean height values (see Falster and Westoby 2003 for details). Based on large scale patterns, we first expected a steady decrease of plant height with altitude. In contrast to different studies which show negative relationship between elevation and plant height (Barrera et al. 2000; Falster and Westoby 2003) a hump shaped pattern was observed (Figure 3D). Previously known negative correlation of tree height with forest spacing (e.g., Kerr 2003) and disturbance (e.g., Villela et al. 2006) is observed in lowlands. Similar pattern for MBA confirms the role of logging in lowlands (Verburg and van EijkBos 2009). Minimum values of MBA and MHC in LoF indicate early successional stage and young age of stands which is apparently caused by logging and selective harvesting in lowlands.
Forest accessibility can affect species diversity along with pattern, frequency and intensity of anthropogenic disturbances such as fuel harvesting, cutting and land-use change (Helmer et al. 2008). The observed reverse hump shaped pattern of disturbance in this study (Figure 3A) coincides with pattern of road density, both hiking and skidding roads, in the area. Road density can act as a logical proxy for forest accessibility (Zumbrunnen et al. 2012). The minimum and maximum peaks of DIS coincide with minimum accessibility in $\mathrm{MiF}$ and MoF except upper edges mainly due to steep slope, and maximum accessibility at lower altitudes respectively (Figure 3A). Other indicators of accessibility including human settlement and flat topography are evident in lower and upper edges of the forest.

The observed pattern of woody species diversity is not exactly in accordance with general consensus of elevational pattern of species richness (McCain and Grytnes 2010). Among the proposed patterns, decreasing woody species diversity with altitude is generally observed (see Rahbek 1995); however, higher species diversity of woody species in LoF is in accordance with diversity plateau at lower elevations hypothesis (Rahbek 1995), which extends to $800 \mathrm{~m}$ a.s.l.. Similar to observed patterns of diversity in the tropics (VázquezGarcia and Givnish 1998; Givnish 1999), mainly due to relatively suitable climatic and edaphic condition in lowlands, which ecologically favors woody life form (Swaine and Becker 1999), LoF shows maximum species richness; however intense disturbance in lower forest edges and little possibility of invasion by exotic woody species, has decreased DIV values (Figure 2B and 3A). Selective logging of dominant species increases the resource and space availability for non-dominant native woody species which consequently leads to an increase in probability of the mentioned taxa to dominate. Another contributing factor to higher diversity at lower belts may be the higher surface area of the mentioned belts (Wang et al. 2007). The complexity behind the diversity patterns, especially in temperate systems including Hyrcanian forest and European deciduous forests has been pointed out by several authors (see Rescia et al. 1994).

The considerable decrease of species richness in LoF-MiF border demonstrates a sharp change in growth condition. This pattern matches with a 
sudden increase in steepness of the slope which occurs above 800-1,000 $\mathrm{m}$ a.s.l.; however, it is not reflected in patterns of other studied parameters. Therefore, the reasons underlying this sudden decrease of species diversity are unclear. There are other sharp shifts in DIV values which occur in transitional vegetations such as Carpinus-Fagus and Fagus-Quercus vegetation types in $\mathrm{MiF}$ and MoF respectively (Figure $2 \mathrm{~B}$ ). We believe that transitional communities, as ecotone vegetations, are generally more diverse a conclusion which is supported by our results. Belts $5-6$ and 9-10 represent an obvious difference in woody species diversity compared to belts 7-8 (Fagus climax community) and 11-12 (Quercus climax community). Ecotone effect (van der Maarel 1990) considers higher species richness for transitional areas due to contribution of neighboring vegetations in the present species pool.

Mid-altitude forest, where minimum value for DIV is observed, is dominated by homogeneous Fagus climax community. Because of inherent properties of this vegetation type such as closed canopy and minimum light availability for shrub and herb canopy layers, diversity of both woody and non-woody species is low (see Davidar et al., 2005). In the last belts where the montane forest of Quercus appears, DIV declines. More stressful condition, thermal constraints (Körner 1998), lower soil depth (Slik et al. 2010) and shorter vegetative season length (Polgar and Primack 2011) are among the most important driving forces of lower woody species diversity montane forest. In addition, long term intensive grazing along with fuel logging of woody species at small scale which occurs in a scattered patchy pattern, play an important role in lower diversity of woody species in high altitudes especially when random sampling methods at small scale are employed (Berry et al. 2008).

\section{Conclusion}

Altitudinal gradients are among the most promising tools for exploring patterns of biological diversity and parameters that influence it. Altitude itself acts as a proxy for different environmental parameters along elevational transects. However, interpretation of observed patterns is normally difficult because of local heterogeneities along the gradient. We conclude that altitude probably acts as a proxy for climatic, edaphic and accessibility factors. Forest accessibility is linked to disturbance intensity in Hyrcanian forest, which itself can deeply affect forest structure and consequently biological diversity. The major driving forces which cause biodiversity and structural differences between lowland and montane forest include precipitation, temperature, season length and soil depth. Temporal stability of warm and humid climate in lowlands favors formation of dense and diverse closed deciduous forest; however, mainly environmental stress in montane forests clearly puts limit on the growth and establishment of woody taxa in highlands. Generally, altitudinal pattern and interactions of biotic and abiotic parameters of forest systems should be considered in management and conservation practices.

\section{References}

Barrera MD, Frangi JL, Richte, LL, et al. (2000) Structural and functional changes in Nothofagus pumilio forests along an altitudinal gradient in Tierra del Fuego, Argentina. Journal of Vegetation Science 11: 179-188. DOI: 10.2307/3236797.

Berry NJ, Philips OL, Ong RC, et al. (2008) Impacts of selective logging on tree diversity across a rainforest landscape: the importance of spatial scale. Landscape Ecology 23: 915-929. DOI: $10.1007 /$ s10980-008-9248-1.

Bodin J, Badeau V, Bruno E, et al. (2013) Shifts of forest species along an elevational gradient in Southeast France: climate change or stand maturation?. Journal of Vegetation Science 24: 269-283. DOI: 10.1111/j.1654-1103.2012.01456.x.

Braun-Blanquet J (1932) Plant sociology, the study of plant communities. New York: McGraw-Hill. p 439.

Clark JA, Covey KR (2012) Tree species richness and the logging of natural forests: A meta-analysis. Forest Ecology and Management 276: 153-146. DOI: 10.1016/j.foreco.2012. 04.001.
Cottam G, Curtis JT (1956) The use of distance measures in phytosciological sampling. Ecology 37: 451-46o. DOI: 10.2307/1930167.

Denslow JS (1995) Disturbance and diversity in tropical rain forest: the density effect. Ecological Applications 5: 962-968. DOI: $10.2307 / 1930167$.

Eshagi Rad J, Shafiei AB (2010) The distribution of ecological species groups in Fagetum communities of Caspian forests: determination of effective environmental factors. Flora 205: 721-727. DOI: 10.1016/j.flora.2010.04.015.

Estevan H, Lloret F, Vayreda J, et al (2007) Determinants of woody species richness in Scot pine and beech forests: climate, forest patch size and forest structure. Acta Oecologica 31: 325331. DOI: 10.1016/j.actao.2007.01.003.

Evans J (2001) The forest handbook. Volume 1: an overview of forest science. Malden: Blackwell Science. p 416.

Falster DS, Westoby M (2003) Plant height and evolutionary games. Trends in Ecology and Evolution 18: 337-343. DOI: 
10.1016/So169-5347(03)00061-2.

Givnish TJ (1999) On the causes of gradients in tropical tree diversity. Journal of Ecology 87: 193-210. DOI: 10.1046/ j.1365-2745.1999.00333.x.

Helmer EH, Brandeis TJ, Lugo AE, et al. (2008) Factors influencing spatial pattern in tropical forest clearance and stand age: Implications for carbon storage and species diversity. Journal of Geophysical Research 113, Go2So4. DOI:10.1029/2007JGoo0568.

IBM Corp. Released 2011. IBM SPSS statistics for windows, version 20.0. Armonk, NY: IBM Corp.

Iran Meteorological Organization (2011) Data and Statistics. Available at: http://www.irimo.ir/.

Johnson EA, Miyanishi K (2007) Plant disturbance ecology: the process and response. Burlington: Elsevier. p 720.

Kerr G (2003) Effects of spacing on the early growth of planted Fraxinus excelsior L. Canadian Journal of Forest Research 33: 1196-1207. DOI: 10.1139/x03-041.

Khaledian Y, Kiani F, Ebrahimi S (2012) The Effect of Land Use Change on Soil and Water Quality in Northern Iran. Journal of Mountain Science 9: 798-816. DOI: 10.1007/s11629-0122301-1.

Khalili A (1973) Precipitation patterns of Central Elburz. Archiv für Meteorologie, Geophysik und Bioklimatologie, Serie B, 21: 215-232. DOI: 10.1007/BFo2243729.

Koch GW, Sillett SC, Jennings GM, et al. (2004) The limits to tree height. Nature 428: 851-854. DOI:10.1038/nature02417.

Körner C (1998) Worldwide position of alpine treelines and their causes. In: Benniston, M., Innes, J.L. (eds.), The impact of climate variability on forests. Berlin: Springer. pp. 221-229.

Lafortezza R, Chen J, Sanesi G, et al. (2008) Patterns and processes in forest landscapes: multiple use and sustainable management. Berlin: Springer. p 452.

Magurran AE (1988) Ecological diversity and its measurement. Princeton: Princeton University Press. p 179.

Mantyka-pringle CS, Martin M, Rhodes J (2012) Interactions between climate and habitat loss effects on biodiversity: a systematic review and meta-analysis. Global Change Biology 18: 1239-1252. DOI: 10.1111/j.1365-2486.2011.02593.x.

McCain CM, Grytnes JA (2010) Elevational gradients in species richness. In: Encyclopedia of life science (eLS). Chichester: John Wiley \& Sons, Ltd. DOI: 10.1002/9780470015902. aoo22548.

Midgley JJ, Niklas KJ (2004) Does disturbance prevent total basal area and biomass in indigenous forests from being at equilibrium with the local environment. Journal of Tropical Ecology 20: 595-597. DOI: 10.1017/So266467404001816.

Mitchel K (2010) Quantitative Analysis by the Point-Centered Quarter Method. Available in Cornell University Library Website: arXiv:1010.3303v1 [q-bio.QM]. (Accessed on 15 December 2011)

Moles AT, Warton DI, Warman L, et al. (2009) Global patterns in plant height. Journal of Ecology 97: 923-932. DOI: $10.1111 /$ j.1365-2745.2009.01526.x.

Moran EF, Brondizio ES, Tucker JM, et al. (2000) Effects of soil fertility and land-use on forest succession in Amazonia. Forest Ecology and Management 139: 93-108. DOI: 10.1016/So3781127(99)o0337-0.

Niklas KJ (2007) Maximum plant height and the biophysical factors that limit it. Tree Physiology 27: 433-440. DOI: 10.1093/treephys/27.3.433.

Pellissier L, Fournier B, Guisan A, et al. (2010) Plant traits covary with altitude in grasslands and forests in the European Alps. Plant Ecology 211: 351-365. DOI: 10.1007/s11258-0109794-X.

Polgar CA, Primack RB (2011) Leaf-out phenology of temperate woody plants: from trees to ecosystems. New Phytologist 191: 926-941. DOI: 10.1111/j.1469-8137.2011.03803.x.

Rahbek C (1995) The elevational gradient of species richness: a uniform pattern?. Ecography 18: 200-205. DOI: 10.1111/ j.1600-0587.1995.tbo0341.x.

Ramezani E, Mohadjer MRM, Knapp HD, et al. (2008) The late-
Holocene vegetation history of the central Caspian (Hyrcanian) forests of northern Iran. Holocene 18: 307-321. Doi: 10.1177/0959683607086768.

Rescia AJ, Schmitz MF, Martín de Agar P, et al. (1994) Influence of landscape complexity and land management on woody plant diversity in northern Spain. Journal of Vegetation Science 5: 505-516. Doi: 10.2307/3235977.

Sahu SC, Dhal NK, Lal B, et al. (2012) differences in tree species diversity and soil nutrient status in a tropical sacred forest ecosystem on Niyamgiri hill range, Eastern Ghats, India. Journal of Mountain Science 9: 492-500. DOI: 10.1007/ S11629-012-2302-O.

Scherer-Lorenzen M, Körner C, Schulze ED (2005) Forest diversity and function: temperate and boreal systems. Ecological Studies, No. 176. Heidelberg: Springer. p 424.

Siadati S, Moradi H, Attar F, et al. (2010) Botanical diversity of Hyrcanian forests; a case study of a transect in the Kheyrud protected lowland mountain forests in northern Iran. Phytotaxa 7: 1-18. DOI: 10.11646/phytotaxa.7.1.

Slik JWF, Aiba SI, Brearley FQ, et al. (2010) Environmental correlates of tree biomass, basal area, wood specific gravity and stem density gradients in Borneo's tropical forests. Global Ecology and Biogeography 19: 50-60. DOI: 10.1111/j.14668238.2009.00489.x.

Swaine MD, Becker P (1999) Woody life form composition and association on rainfall and soil fertility gradients in Ghana. Plant Ecology 145: 167-173. DOI: 10.1023/A:1009829518561.

Takeuchi T, Kobayashi T, Nashimoto M (2011) Altitudinal differences in bark stripping by sika deer in the subalpine coniferous forest of Mt. Fuji. Forest ecology and Management 261: 2089-2095. DOI: 10.1016/j.foreco.2011.03.002.

Takyu M, Kubota Y, Aiba SI, et al. (2005) Pattern of changes in species diversity, structure and dynamics of forest ecosystems along altitudinal gradients in East Asia. Ecological Research 20: 287-296. DOI: 10.1007/s11284-005-0044-y.

Ter Steege HT, Pitman N, Sabatier D, et al. (2003) A spatial model of tree alpha-diversity and tree density for the Amazon. Biodiversity and Conservation 12: 2255-2277. DOI: 10.1023/ A:1024593414624.

Tromp van Meerveld HJ, McDonnell JJ (2006) On the interrelations between topography, soil depth, soil moisture, transpiration rates and species distribution at the hillslope scale. Advances in Water Resources 29: 293-310. DOI: 10.1016/j.advwatres.2005.02.016.

van der Maarel E (1979) Transformation of cover - abundance values in phytosociology and its effects on community similarity. Vegetatio 39: 97-114. DOI: 10.1007/BFoo052021.

van der Maarel E (1990) Ecotones and ecoclines are different. Journal of Vegetation Science 1: 135-138. DOI: 10.2307/ 3236065 .

Vázquez-Garcia JA, Givnish TJ (1998) Altitudinal gradients in tropical forest composition, structure, and diversity in the Sierra de Manantlán. Journal of Ecology 86: 9991020. DOI: 10.1046/j.1365-2745.1998.00325.x.

Verburg R, van Eijk-Bos C (2003) Effects of selective logging on tree diversity, composition and plant functional type patterns in a Bornean rain forest. Journal of Vegetation Science 14: 99110. DOI: $10.1111 /$ j.1654-1103.2003.tbo2132.x.

Villela DM, Nascimento MT, de Aragao LEOC, et al. (2006) Effect of selective logging on forest structure and nutrient cycling in a seasonally dry Brazilian Atlantic forest. Journal of Biogeography 33: 506-516. DOI: 10.1111/j.1365-2699.2005. 01453.x.

Wang Z, Tang Z, Fang J (2007) Altitudinal patterns of seed plant richness in the Gaoligong Mountains, south-east Tibet, China. Diversity and Distribution 13: 845-854. DOI: 10.1111/ j.1472-4642.2007.00335.x.

Zumbrunnen T, Menendez P, Bugmann H, et al. (2012) Human impacts on fire occurrence: a case study of hundred years of forest fires in a dry alpine valley in Switzerland. Regional Environmental Change 12: 935-949. DOI: $10.1007 / \mathrm{s} 10113^{-}$ 012-0307-4. 
Appendix 1 List of woody taxa in Hyrcanian forest (recorded in this study)

\begin{tabular}{|c|c|c|}
\hline \multicolumn{3}{|c|}{ Woody Taxa mentioned recorded in this study } \\
\hline Acer campestre L. & Gleditsia caspica Desf. & Taxus baccata L. \\
\hline Acer cappadocicum Gled. & Mespilus germanica L. & Tilia platyphyllos Scop. \\
\hline Acer hyrcanum Fisch. \& C.A.Mey. & Parrotia persica C.A.Mey. & Ulmus glabra Huds. \\
\hline Acer velutinum Boiss. & Populus caspica (Bornm.) Bornm. & Ulmus minor Mill. \\
\hline Albizia julibrissin Durazz. & Prunus laurocerasus L. & Alnus subcordata C.A.Mey. \\
\hline Alnus glutinosa (L.) Gaertn. & Pterocarya fraxinifolia (Poir.) Spach & Cornus australis C.A.Mey. \\
\hline Buxus hyrcana Pojark. & Pyrus boissieriana Buhse & Ilex spinigera Loes \\
\hline Carpinus betulus L. & Quercus castaneifolia C.A.Mey. & Cratagus monogyna Jacq. \\
\hline Carpinus orientalis Mill. & $\begin{array}{l}\text { Quercus macranthera Fisch. \& } \\
\text { C.A.Mey. }\end{array}$ & $\begin{array}{l}\text { Crataegus pentagina Wladst. \& Kit. } \\
\text { ex Willd. }\end{array}$ \\
\hline Diospyros lotus L. & Cupressus sempervirens L. & Sorbus torminalis (L.) Crantz \\
\hline Fagus orientalis Lipsky & Ruscus hyrcanus Woro & $\begin{array}{l}\text { Frangula grandifolia (Fisch. \& } \\
\text { C.A.Mey) Grubov }\end{array}$ \\
\hline Ficus carica L. & Salix alba L. & Lonicera caucasica Pall. \\
\hline Fraxinus excelsior L. & Robinia pseudoacacia L. & Vaccinium arctostaphylos L. \\
\hline
\end{tabular}

\section{Appendix 2}

In order to calculate importance-value of species using point centered quarter method, three parameters of relative density, relative frequency and relative cover or dominance are generated using related statistical formulas (Mitchel 2010). The absolute density parameter for a forest stand; the number of trees per unit area, is statistically based on distance to center values in each quarter. In this step, the mean distance is calculated which is the sum of the nearest neighbor distances in the quarters surveyed divided by the number of quarters (Equation 1). Consequently, an estimate of forest stem density is calculated (Equation 2). The presence/absence data of each species in the quarters is used for estimation of relative density (Equation 3).

In point centered quarter method, the absolute frequency of species is a function of number of sampling points with that species (Appendix 2: Equation 4). The relative frequency of taxa equals to absolute frequency of each species divided by sum of absolute frequency of all species (Equation 5). Similarly, the cover or dominance of species is a function of basal area of that species which can be calculated using circumference at breast height values (Equation 6). Dividing total basal area of each species by total basal area of all taxa generates relative cover or dominance of that species (Equation 7). Finally, by summing three parameters, Importance-Value of species was calculated:

Importance value $=$ relative density + relative frequency + relative cover

\begin{tabular}{|c|c|}
\hline Formula & Details \\
\hline$M d=\frac{\sum d}{4 n}$ & $\begin{array}{l}M d=\text { Mean distance } \\
d=\text { distance to center } \\
n=\text { number of sampling points }\end{array}$ \\
\hline$A D($ forest $)=\frac{1}{M d^{2}}$ & $\begin{array}{l}A D=\text { Absolute density } \\
M d=\text { Mean distance }\end{array}$ \\
\hline$R D($ species $i)=\frac{Q}{4 n} \times 100$ & $\begin{array}{l}Q=\text { number of quarters in which species is } \\
\text { present } \\
n=\text { number of sampling points }\end{array}$ \\
\hline$A F($ Species $i)=\frac{n(\text { Species } i)}{N} \times 100$ & $\begin{array}{l}\text { AF }(\text { Species } i)=\text { Absolute frequency of species } i \\
n(\text { species } i)=\text { number of sampling points with } \\
\text { species } i \\
N=\text { total number of sampling points }\end{array}$ \\
\hline$R F($ Species $i)=\frac{A F(\text { species } i)}{\sum A F(\text { species } i-k)} \times 100$ & $\begin{array}{l}R F(\text { Species } i)=\text { Relative frequency of species } i \\
A F(\text { Species } i)=\text { Absolute frequency of species } i\end{array}$ \\
\hline$B A=\frac{C^{2}}{4 \pi}$ & $\begin{array}{l}B A=\text { Basal area } \\
C=\text { Circumference at breast height }\end{array}$ \\
\hline$R C($ Species $i)=\frac{\sum B A(\text { Species } i)}{\sum B A(\text { Species } i-k)} \times 100$ & $\begin{array}{l}R C(\text { Species } i)=\text { Relative cover of species } i \\
B A=\text { Basal area }\end{array}$ \\
\hline
\end{tabular}

